\title{
Norois
}

Environnement, aménagement, société

$247 \mid 2018$

Recherche touristique : perspectives latinoaméricaines

\section{Gustavo Marín Guardado (coord.), Sin tierras no hay paraíso. Turismo, organizaciones agrarias y apropiación territorial}

Maxime Kieffer

\section{(2) OpenEdition}

\section{Journals}

Édition électronique

URL : http://journals.openedition.org/norois/6769

DOI : $10.4000 /$ norois. 6769

ISBN : 978-2-7535-7629-2

ISSN : $1760-8546$

Éditeur

Presses universitaires de Rennes

Édition imprimée

Date de publication : 19 septembre 2018

Pagination : 107-109

ISBN : 978-2-7535-7570-7

ISSN : 0029-182X

Référence électronique

Maxime Kieffer, «Gustavo Marín Guardado (coord.), Sin tierras no hay paraíso. Turismo, organizaciones agrarias y apropiación territorial », Norois [En ligne], 247 | 2018, mis en ligne le 19 septembre 2018, consulté le 05 janvier 2021. URL : http://journals.openedition.org/norois/6769 ; DOI : https://doi.org/ 10.4000/norois. 6769 


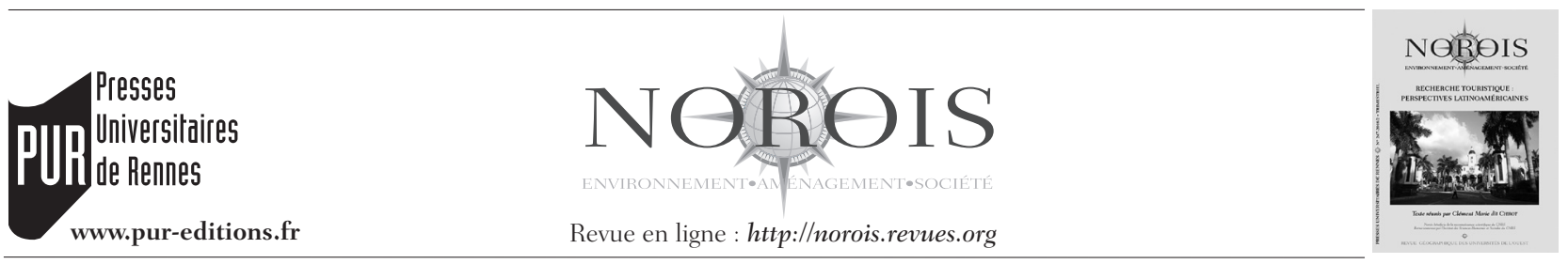

\section{COMPTE RENDU BIBLIOGRAPHiQue}

Gustavo Marín Guardado (coord.), 2015. Sin tierras no hay paraíso. Turismo, organizaciones agrarias y apropiación territorial, [http://www.pasosonline.org/Publicados/pasosoedita/ PSEdita 15.pdf]

Avec 35 millions de touristes étrangers arrivés en 2016 (Secretaría de turismo, 2017), le Mexique occupe actuellement le $10^{\mathrm{e}}$ rang mondial en termes d'arrivées internationales. Ses côtes paradisiaques, ses régions intérieures aux riches cultures traditionnelles et la grande diversité de ses ressources naturelles attirent donc de plus en plus de touristes. Les lieux du tourisme rural correspondent souvent à des territoires peuplés de communautés indigènes ou paysannes qui ont établi historiquement un régime collectif de possession et d'utilisation de la terre et des ressources naturelles (terres communales ou ejidos). L'arrivée du tourisme sur ces territoires remet en question et menace la relation à la terre et les modes de vies des populations locales. Comme le montrent les études présentées dans ce livre, les lieux aux apparences idylliques que visitent les touristes sont souvent le résultat d'expropriations violentes, de spoliations de terres ou de négociations difficiles entre l'État, les populations locales, les entrepreneurs privés et leurs intermédiaires. Le tourisme, qui s’inscrit dans le cadre d'une lutte pour le territoire et son contrôle, amène dans ce pays qui connaît de profonds conflits sociaux une manne économique et de nombreuses promesses de développement, intensifiant souvent des problèmes déjà existants ou en créant de nouveaux.

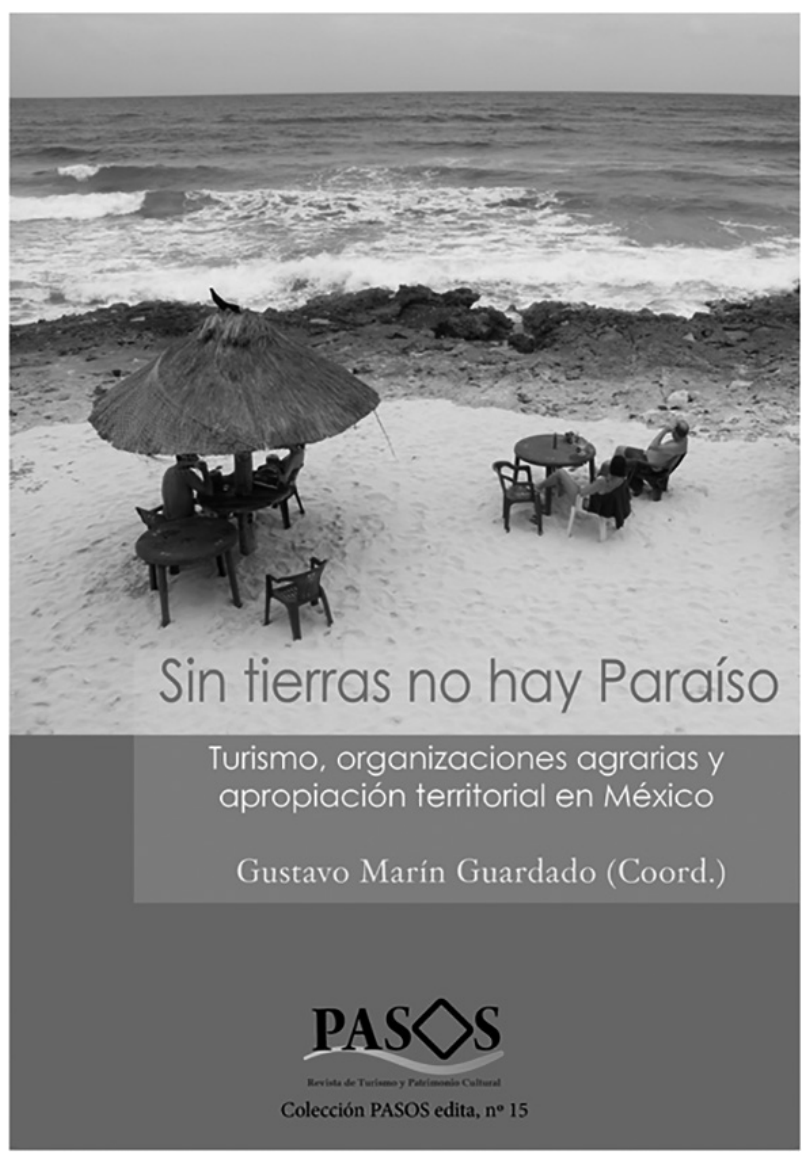


Ce recueil de neuf articles aborde le thème des impacts de la mise en tourisme de régions rurales et plus particulièrement la lutte pour l'appropriation des terres liée aux enjeux du tourisme dans le Mexique contemporain. Il se veut complémentaire de nombreuses études qui se sont intéressées au cours de la dernière décennie aux impacts socioculturels du tourisme à travers la perception des acteurs, cherchant à redonner toute leur importance aux processus de contrôle territorial mis en place.

Gustavo Marín Guardado revient en introduction sur l'histoire récente du tourisme au Mexique et sur les modalités de mise en tourisme qui ont conduit à la conformation du paysage touristique actuel. Il décrit trois phases schématiques : la consolidation de l'industrie touristique au milieu du $\mathrm{xx}^{\mathrm{e}}$ siècle avec l'arrivée de touristes américains après la seconde guerre mondiale, le développement qui s'ensuivit du tourisme de masse sur les côtes du pays dans les années 1970 et enfin l'étape qui débute dans les années 1990 et continue de nos jours, celle du développement de l'écotourisme dans toutes les régions du pays. Chacune de ces phases a donné lieu à des luttes d'appropriation du territoire dont la nature est liée à l'histoire foncière, juridique et politique du pays. Dès la naissance du tourisme en zones rurales, le problème de la terre se pose en termes de conflits sociaux en raison des inégalités présentes entre les communautés rurales marginales et les promoteurs et acteurs du tourisme venus des villes et de la bourgeoisie qui exploitent les ressources des communautés et pratiquent la spéculation foncière. Dans les années 1970, un nouveau modèle de développement touristique s'impose, soutenu par les organismes internationaux qui présentent le tourisme comme une solution de développement économique et une voie de sortie à la pauvreté pour les nations émergentes comme le Mexique, avec intervention de l'État qui met en place cinq Centres Intégralement Planifiés de tourisme de plage venant s'ajouter aux centres traditionnels. L'expropriation est la règle, l'État mettant à disposition du Fonds National de Développement du Tourisme (FONATUR, créé en 1974) les terres obtenues, et les revendant ensuite à des entreprises privées nationales et étrangères, détournant la loi qui interdit la vente de terres côtières aux étrangers à travers la figure juridique des fideicomisos, afin de favoriser les investissements et le développement économique. À l'expropriation s'ajoutent des pratiques frauduleuses et illégales de la part de la classe politique et entrepreneuriale qui s'approprie les territoires de communautés rurales à moindre coût. La modification en 1992 de l'article 27 de la Constitution sur les terres communales, qui permet désormais de parceller et vendre la terre, a accéléré la privatisation des terres et conduit, à travers la mise en tourisme, à une mercantilisation de l'espace naturel et culturel. Marín appelle ce processus « la spoliation intégralement planifiée » (el despojo integralmente planificado), car la répétition des modes d'appropriation est telle qu'on a réellement affaire à un programme systématique et non à des cas isolés. Preuves en sont les nombreux exemples de conflits dans lesquels les populations locales réclament des restitutions à l'État, aux investisseurs et entrepreneurs privés de l'industrie touristique.

La phase qui commence à la fin des années 1980 correspond à un retrait de l'État des zones de plage au profit de l'entreprise privée et un investissement accru dans le tourisme intérieur sous forme de projets de tourisme durable, écotourisme, tourisme communautaire, l'État mexicain cherchant par-là, à diversifier l'offre touristique et à lier le tourisme à la conservation des ressources naturelles et au développement local. Cette phase n'est pas exempte d'instrumentalisation : "Tourisme et protection de l'environnement constituent une formule parfaite qui a été promue comme faisant partie des nouvelles modalités du tourisme alternatif et du développement durable; et en même temps elle a été l'un des points sur lesquels s'appuie le capital international pour accéder aux territoires à travers des politiques interventionnistes et des pratiques d'expropriation» (p. 12). Les pratiques de corruption, d'« invisibilisation » (Almanza Alcalde, p. 118) ou de criminalisation (Bastos Amigo, p. 201) des communautés locales et plus particulièrement indigènes, l'absence de transparence au niveau juridique et légal, ajoutées aux réseaux d’intérêts politico-économiques, continuent à fonder un régime de domination, d'oppression et de répression qui ne laisse pas présager de beaux lendemains pour les communautés dans le point de mire de l'industrie touristique.

Comme le montre l'un des articles du livre (Ana García et al.), bien que ses bases théoriques le définissent comme une forme de mise en 
développement favorable aux communautés locales, le tourisme alternatif pose aussi des questions cruciales sur le thème de l'ingérence et la résolution des conflits autour du territoire et de sa gestion. Les problèmes sont d'autant plus profonds que le monde rural mexicain vit depuis des décennies une crise agraire aux multiples conséquences (pauvreté, abandon des campagnes, exode rural et émigration, narcotrafic, perte de repères et d'identité, etc.). Les populations locales se trouvent ainsi face à des prises de décision difficiles en ce qui concerne leur souveraineté territoriale car les structures qui pourraient les soutenir ont été fragilisées au cours des dernières décennies, donnant beaucoup de pouvoir aux investisseurs extérieurs et les laissant avec une marge de manœuvre toujours plus réduite.

Les travaux présentés dans le livre offrent une variété de sites de recherches: Holbox (Quintana Roo), Rebalsito (Jalisco), Tulum (Quintana Roo), la Sierra Tarahumara (Chihuahua), Mezcala (Jalisco), cinq sites de tourisme alternatif de la péninsule du Yucatan, une étude comparative entre Huatulco (Oaxaca) et Playa del Carmen (Quintana Roo), Cabo San Lucas (Baja California Sur). Chaque contexte singulier montre la complexité des relations qui entrent en jeu quand il s'agit de lutte pour le territoire et met en valeur une série de facteurs explicatifs des processus que déclenche la mise en tourisme d'un territoire rural. Comme le dit Marie dit Chirot, le tourisme s'articule sur des dynamiques conflictuelles déjà existantes : « en aggravant certaines contradictions sociales liées à l'espace, le tourisme se transforme en scène de conflit social et politique »(271). Les angles d'approche sont principalement ceux de la sociologie, l'anthropologie et la géographie, ce qui donne une grande richesse à l'ouvrage malgré une certaine homogénéité de points de vue et la citation des mêmes références théoriques (Harvey pour l'accumulation par dépossession, Santillan et Marín). Cependant, comme le dit Marín dans l'introduction, l'engrenage se répète avec tant de persistance qu'il est difficile de concevoir l'appropriation foncière dans le cadre du tourisme au Mexique autrement que sous l'angle de la spoliation, de l'expropriation et des luttes inégales de pouvoir.

Maxime KIEFfER université Nationale Autonome du Mexique (UNAM - ENES Morelia)

Cette contribution s'inscrit dans le cadre du projet ECOS-Nord intitulé «Développement local et conservation: une analyse des enjeux des politiques de lutte contre la pauvreté par le tourisme alternatif dans l'État du Yucatan au Mexique», porté par l'université d'Angers et l'université Nationale Autonome du Mexique (UNAM, campus Morelia). 